\title{
Políticas de informação ergonômicas voltadas ao trabalhador de arquivos e bibliotecas
}

\author{
Joana Coeli Ribeiro Garcia \\ Universidade Federal do Pará, Brasil \\ Marilia Vital Ribeiro \\ Universidade Federal do Pará, Brasil
}

ORIGINAL

\begin{abstract}
Resumo
Objetivo. O estudo tem como principal objetivo verificar a implementação de políticas de informação ergonômicas nos arquivos e bibliotecas de instituições públicas de ensino superior no município de João Pessoa.

Método. Para realização desta pesquisa, foram realizadas a observação direta das condições de trabalho nos arquivos e bibliotecas de Instituições de Ensino Superior (IES) públicas do município de João Pessoa, a leitura do Plano de Desenvolvimento Institucional (PDI) vigente em cada uma das IES e entrevistas com os trabalhadores destes setores com base em roteiro apoiado nas categorias estabelecidas pela Norma Regulamentadora 17, a fim de compreender quais são suas percepções em relação à adoção ou ausência de políticas ergonômicas dos referidos setores nas instituições analisadas.

Resultados. Os resultados estão apresentados em duas etapas. Em primeiro lugar, aqueles obtidos por meio da leitura e análise dos Planos de Desenvolvimento Institucional das instituições estudadas, para identificar metas e ações voltadas para a ergonomia. Em seguida, por meio do método de codificação e utilização de palavras-chave, as entrevistas realizadas com servidores que atuam nos setores de arquivo e biblioteca das instituições, visando conhecer suas percepções sobre a atuação da instituição em relação ao (des)cumprimento das normas de ergonomia em seus ambientes de trabalho e identificar as políticas de informação ergonômicas adotadas em seus arquivos e bibliotecas.

Conclusões. Os resultados apontam a insuficiência de políticas de informação ergonômicas nas instituições, e essa situação reflete na insatisfação de alguns servidores quanto às suas condições de trabalho, evidenciando a necessidade de as instituições repensarem suas políticas em ergonomia, adequando seus ambientes de trabalho às características dos trabalhadores e instituindo programas e ações direcionados à ergonomia, saúde e segurança do trabalho.
\end{abstract}

Palavras-chave:

Ergonomia em arquivo; Ergonomia em biblioteca; Ergonomia e Ciência da Informação; Política de informação ergonômica; Precarização do trabalho.

\section{Ergonomic information policies for archives and libraries workers}

\begin{abstract}
Objective. The main objective of the study is to verify the implementation of ergonomic information policies in the archives and libraries of public institutions of higher education in the city of João Pessoa.

Method. In order to carry out this research, direct observation of working conditions was carried out in the archives and libraries of public institutions of higher education in the city of João Pessoa, the Institutional Development Plan in force in each of the HEls was also read, and finally, workers in these sectors were interviewed based on a script supported by the categories established by Regulatory Norm 17, in order to understand what their perceptions are in relation to the adoption or absence of ergonomic policies of the referred sectors in the analyzed institutions.

Results. The results are presented in two stages. First, those obtained through reading and analyzing the Institutional Development Plans (PDI) of the higher education institutions studied, to identify goals and actions focused on ergonomics. Then, through the method of coding and using keywords, the interviews conducted with servers that work in the archives and library sectors of the institutions, in order to know their perceptions about the institution's performance in relation to (non)compliance ergonomics norms in their work environments and to identify the ergonomic information policies adopted in the institutions' archives and libraries.

Conclusions. The results point to the insufficiency of ergonomic information policies in the institutions, and this situation reflects the dissatisfaction of some employees regarding their working conditions, showing the need for institutions to rethink their ergonomic policies, adapting their work environments to the characteristics of workers and instituting programs and actions aimed at ergonomics, health and safety at work.
\end{abstract}

Keywords:

Ergonomic information policies; Ergonomics and Information Science; Ergonomics in archives; Ergonomics in libraries; Precarious work. 


\section{Introdução}

A necessidade de adequação e aperfeiçoamento de equipamentos utilizados no exercício das atividades laborais são percebidos desde os primórdios das civilizações. No entanto, o campo científico da ergonomia, direcionado à adequação e otimização das condições do ambiente de trabalho versus o bem estar físico e psiquico dos trabalhadores, surge somente no final da década de 1940.

Em análise sobre a ciência da informação, Araújo (2018) aponta seis subáreas que, para ele, a compõe. São elas: comunicação científica, representação da informação, usuários da informação, gestão da informação, economia política da informação e bibliometria. Destaca-se a proximidade entre a temática discutida no presente artigo com a subárea da economia política da informação. Autores voltam-se aos estudos das políticas de informação, não apenas em seus aspectos normativos ou operacionais, mas considerando sua inter-relação com as dimensões social, cultural, econômica e política da vida humana.

Segundo Bezerra e Silva (2015, p. 02), pode-se afirmar que, "na sociedade contemporânea, o campo teórico da gestão e política de informação abre cada vez mais a discussão sobre o valor da informação e a necessária democratização do acesso às suas fontes de informação". Nesse sentido, o processo de criação de políticas de informação ergonômicas seria idealizado pelo Estado, que com base em orientações fornecidas por organismos internacionais ou por necessidades específicas de determinadas classes profissionais - digitadores, por exemplo, cujas demandas estimularam a criação da norma regulamentadora NR - 17, define quais políticas e quais diretrizes serão adotadas para regulamentar as condições de trabalho. Em seguida, as instituições públicas e privadas adequam-se às recomendações do ente estatal e promovem as mudanças necessárias ao atendimento dos princípios ergonômicos nos ambientes de trabalho, possibilitando melhor qualidade de vida dos trabalhadores e redução de custos financeiros gerados por afastamentos, licenças e aposentadorias precoces em virtude de condições inadequadas de trabalho.

A pesquisa de Araújo (2018), inclui a subárea da recuperação da informação, que também aproxima-se da temática aqui trabalhada, pois nela ocorre a revalorização de estudos focados na interação humano-máquina e em aspectos relacionados à ergonomia, usabilidade e inteligência artificial. Nota-se ainda afinidade entre os assuntos discutidos com a gestão da informação, posto que, segundo Araújo (2018, p. 60), "o conhecimento não é algo individual, isolado: os conhecimentos tácitos das pessoas que compõem as organizações são construídos coletivamente, aplicados no contexto de intervenções concretas dos sujeitos interagindo uns com os outros". Entende-se então que a cultura organizacional constitui recurso nas organizações, definindo formas de pensar e de agir, tanto quanto valores, crenças, informações e conhecimentos valorizados naquela instituição. Tal ideia remete ao campo da ergonomia organizacional, que considera os trabalhadores integrantes da cultura organizacional, cujas influências externas e internas repercutem em seus comportamentos e atitudes.

Desde sua formação, arquivistas e bibliotecários desenvolvem as seguintes habilidades e competências que farão parte de sua vida profissional: coletar informações relevantes, pesquisar, organizar, armazenar, recuperar, avaliar, selecionar, interpretar informações, disseminar e tratá-las de forma sistemática e estruturada para potenciar os usos (FINAMOR; LIMA, 2017). Tais informações são dispostas nos mais diversos tipos de suportes físicos, que incluem do papel aos meios digitais. Essa variedade de meios onde as informações são registradas demandam condições ambientais, tratamentos técnicos e mobiliários adequados, não apenas para acomodar materiais informacionais, mas inclusive para atender às demandas de adequação das condições de trabalho às características psicofisiológicas dos profissionais, objetivo principal da ergonomia.

Aspectos esses que proporcionam a pesquisa sobre a reflexão dos impactos que a presença ou ausência de políticas ergonômicas nos setores de arquivos e bibliotecas geram nos profissionais que trabalham nesses ambientes, buscando responder à seguinte questão: Como as instituições públicas de ensino superior desenvolvem políticas de informação ergonômicas voltadas para arquivos e bibliotecas? Adotando por objetivo macro: verificar implementação e/ou o desenvolvimento de políticas de informação ergonômicas nos arquivos e bibliotecas de instituições públicas de ensino superior da cidade de João Pessoa - Paraíba, Brasil.

Estudos sobre políticas institucionais voltadas para a questão trabalho-saúde são fundamentais para a conscientização tanto dos trabalhadores, quanto das instituições que os emprega, portanto, devem ser incentivados, tendo em vista os benefícios que conduzem. Além das reflexões sobre o papel da ergonomia para a saúde do trabalhador de arquivo e de biblioteca não se limitar a aspectos físicos ou fisiológicos dos instrumentos de trabalho, mas abranger toda a complexidade desse universo, que inclui aspectos subjetivos de natureza organizacionais, cognitivos e sociais. 
De forma específica, reflexões em políticas de informação ergonômicas devem ser estimuladas, de modo que os profissionais disponham de conhecimentos capazes de melhorar sua qualidade de vida no trabalho. São razões que levam a considerar esta pesquisa desafiadora e inovadora, pois inexiste literatura refletindo estudos sobre relações entre ergonomia, ciência da informação e política, contemplando aspectos de sua proximidade com a arquivologia e a biblioteconomia.

\section{Sobre Ergonomia}

A origem e o desenvolvimento da Ergonomia relacionam-se às transformações sociais, econômicas e tecnológicas observadas ao longo do tempo no mundo do trabalho (WACHOWICZ, 2013). Na fase pré-histórica, há indícios de intervenção humana para adequação e adaptação de ferramentas utilizadas para a caça, a coleta e para o aperfeiçoamento de artefatos necessários às tarefas de subsistência. O formato e o material, madeira, pedra, ferro de que se fabricavam os instrumentos, eram escolhidos em função de suas características, do efeito desejado tais como precisão, força etc, além dos atributos dos homens que os manejavam, como a dimensão da mão, potência muscular a ser utilizada, o controle da massa que iria movimentar e outros mais.

Embora não houvesse, naquele período, a sistematização da ergonomia, conhecimentos empíricos e parciais da disciplina foram considerados para o aperfeiçoamento dos instrumentos (LAVILLE, 1977). A Revolução Industrial trouxe a substituição gradual do trabalho manual e lento pela produção em série e mecanizada. Situação que agravava o problema de adequação dos instrumentos aos trabalhadores, porquanto as fábricas eram superlotadas e os operários confinados em ambientes sujos, escuros e insalubres. Os operadores de instrumentos eram submetidos a humilhações e castigos, riscos constantes, incluindo acidentes e propagação de doenças. Somado a isso, a inexistência de sindicatos e de direitos trabalhistas obrigavam homens, mulheres e crianças a execução de jornadas de trabalho que podiam chegar a dezesseis horas diárias. Da mesma forma, inexistia férias, direito a licenças, folgas, décimo terceiro salário ou salário mínimo (IIDA, 2005).

Em torno de 1900 surgem estudos sobre fisiologia do trabalho. Os pesquisadores se preocupam em analisar as consequências das condições penosas de trabalho, especialmente aquelas realizadas em ambientes insalubres, minas de carvão e fundições. Em 1913, na cidade de Dortmund, na Alemanha, Max Ruber criou um centro voltado aos estudos em fisiologia do trabalho, hoje chamado Instituto Max Plank de Fisiologia do Trabalho e responsável por avanços na área, tendo desenvolvido metodologias e instrumentos para a medição dos gastos energéticos durante o exercício das atividades ocupacionais (IIDA, 2005).

Historicamente, o termo ergonomia foi utilizado pela primeira vez em um manifesto filosófico proferido em 1857 pelo polonês Wojciech Jarstembowski e surgiu a partir da união entre os termos ergo (trabalho) e nomos (normas, regras) (CARVALHO; SALDANHA; VIDAL, 2017). Entretanto, somente em 1949, quase cem anos após sua criação, ocorre sua primeira utilização. O termo passou a ser usado para definir um campo específico do saber, com objeto e objetivos próprios, através da criação da Ergonomics Research Society, em Oxford.

A ergonomia nasce com características interdisciplinares de aplicação prática e busca transformar o trabalho, adaptando-o aos limites e especificidades do ser humano. Alcançar o bem-estar e a segurança dos indivíduos são compromissos éticos assumidos pelo campo do saber, superando a noção taylorista de "Homo economicus" ao estabelecer que a maior motivação para o cumprimento de metas é o estímulo financeiro. Pensamento que desconsidera influências do comportamento humano em relação ao trabalho (ABRAHÃO et al., 2016).

Segundo Verdussen (1978) existem, no ambiente de trabalho, fatores principais e secundários que atuam em sua constituição. A temperatura, os ruídos, as vibrações, os odores e as cores são exemplos de fatores principais, enquanto a arquitetura, as relações humanas, a remuneração, a estabilidade e o apoio social constituem fatores secundários. Os ergonomistas analisam o trabalho de forma global incorporando elementos físicos, cognitivos, sociais, organizacionais e ambientais que o afetam. São responsáveis por planejar, projetar e avaliar tarefas, postos de trabalho, produtos, ambientes e sistemas, para que se tornem compatíveis com as necessidades e as limitações dos indivíduos. Tais profissionais também estudam as consequências do trabalho em relação a vida das pessoas, incluindo fatores organizacionais, porquanto boa parte das decisões que afetam o trabalho partem do nível gerencial (IIDA, 2005).

O processo de industrialização trouxe consequências técnicas, econômicas e sociais que transformaram o modo de produção, provocando mudanças na mentalidade empresarial, antes alheia às necessidades dos indivíduos. Influenciadas pelo olhar tecnicista, as intervenções ergonômicas buscam aumentar o rendimento e a produção, mediante a sistematização de movimentos e tarefas a fim de obter o máximo, em menor tempo. Havia notáveis esforços em aperfeiçoar o binômio humano-máquina, desconsiderando aspectos subjetivos dos indivíduos, que 
eram forçados a se ajustarem às máquinas ou às funções a que eram delegados. Não se atentava para aspectos individuais, fisiológicos, psicológicos e ambientais que influenciavam as condições de trabalho (VERDUSSEN, 1978).

Para Verdussen (1978, p. 01), essa mudança de perspectiva fez com que se percebesse que "o homem como peça fundamental do sistema de produção, gradualmente alterou conceitos, surgindo o cuidado de adequar o trabalho, o equipamento e o meio ao homem", ou seja, usar ou adotar ergonomia. Tais mudanças compreendem que o trabalho deve ampliar seu leque de visão, de modo que este não seja visto somente por um meio de subsistência, mas percebendo-o como forma de obter satisfação pessoal (VERDUSSEN, 1978).

Em 1980, os avanços da Informática impuseram novos desafios à ergonomia. A popularização do computador pessoal, os softwares, o hipertexto e a velocidade de produção e disseminação de informações e documentos transformaram profundamente os hábitos e rotinas de várias profissões. As atividades passaram a ser mais monótonas e sedentárias, tendo em vista que, de um bureau com computador era possível realizar múltiplas tarefas com mínimo deslocamento. As inovações provocadas pelas tecnologias, segundo Moraes e Mont'Alvão (2009, p. 17), ocasionaram, por um lado "uma sobrecarga pela intensificação do ritmo de trabalho e, por outro, uma subcarga pela monotonia”. Essas situações contribuíam para aumentar as possibilidades de erro, de problemas físicos e psíquicos nos profissionais.

Por mais avançado que seja, um computador ainda depende do fator humano para interpretar as informações e tomar as decisões necessárias. Moraes e Mont'Alvão (2009, p. 18) lembram que um sistema "por mais informatizado e eficaz que seja, será um fracasso se o controlador não puder regulá-lo com rapidez, segurança e eficiência". Assim, ao longo do tempo, a área da ergonomia se adequa ao uso das tecnologias, de modo a fornecer orientações necessárias para que o processo de sua inserção nas práticas e rotinas laborais seja menos penoso aos envolvidos.

\subsection{Política de informação ergonômica}

A informação tornou-se tema de fundamental importância em várias esferas de discussão e em diversos segmentos da sociedade, tais como, o político, o econômico, o cultural, o social e o ambiental, principalmente a partir do século XX (SILVA; SILVA; FREIRE, 2018). A informação assume um papel relevante na sociedade atual, pois se configura como fenômeno estruturante de práticas sociais, políticas e econômicas dentro de uma coletividade. Além disso, reflete diretamente sobre a formação política de uma sociedade, protagonizando as políticas de informação, que constituem aspectos condicionantes da produção e consumo de informação e de criação de conhecimento (BEZERRA; SILVA; GUIMARÃES; SOUZA, 2016).

A informação possui relação direta com a política e com o poder. Ao discutir seu papel na perspectiva da tomada de decisões, sejam elas administrativas ou relacionadas às políticas públicas, é possível perceber a predominância de uma visão utilitarista, ofuscando as variáveis que influenciam o fenômeno informacional, como a capacidade cognitiva do sujeito, as relações de poder, conflito e adesão que atuam no contexto da busca de informações (SILVA, E., 2016).

Na década de 50, a relação entre política e informação passa a ser explicitada por meio de programas de governo e de políticas públicas, estabelecendo-se por dupla referência ao estado e a "constituição comunicacional", de realização flexibilizada e desigual. A política de informação surge por temática e domínio de relativa autonomia no cenário do pós-guerra, associada às de ciência e tecnologia. A relação entre informação e política seria definida por meio de sua inclusão em esfera de intervenção estatal, fator estratégico para o desenvolvimento científico e tecnológico (GONZÁLEZ DE GOMEZ, 2002).

Uma política de informação deve traduzir as direções a serem tomadas com base nas demandas e necessidades da sociedade que necessitam de leis, regulamentos ou programas que exerçam mediação entre a sociedade e o governo (BRAMAN, 2006). Informação e política denotam o sentido de ordem e regulação. A reunião destes dois vocábulos formando o conceito de políticas de informação. (FREIRE, 2010).

Segundo Frohmann (2008, p. 21), "em geral, os indivíduos não são os agentes primários dos processos do interesse dos estudos dos aspectos sociais, públicos, econômicos e culturais da informação". Embora a política de informação tenha surgido pela necessidade de os estados promoverem avanços científicos e tecnológicos, ao longo do tempo sua abrangência foi ampliada, passando-se a considerar também sua aplicação em relação à sociedade e às organizações estatais e não estatais, bem assim a contribuição para a melhoria dos níveis educacional, cultural e político (DUTRA; CORREA; RUAS, 2013). 
Segundo Braman (2006, p. 18), "a política de informação molda fundamentalmente as condições nas quais empreendemos todas as outras atividades políticas, sociais, culturais e econômicas”. É por meio dela que o governo exerce o poder informacional, considerado pela autora como a mais importante atualmente.

As transformações percebidas ao lidar com a tríade saúde/doença/cuidado têm relação com as mudanças político-sociais e econômicas presentes na constituição do estado moderno, em um crescente processo de urbanização e de organização da sociedade capitalista (MORAES; GONZÁLEZ DE GOMEZ, 2007). Portanto, as políticas de informação em saúde refletem a relação existente entre poder, política e informação e, segundo Braman (2006, p. 37), "esse impacto da criação de informação, processamentos, fluxos e uso é que faz a política de informação tão fundamental para exercício do poder".

Inicialmente, as políticas de informação podem ser consideradas principiológicas, pois toda e qualquer política requer, direta ou indiretamente, um conjunto de princípios, leis, diretrizes, regulamentos e procedimentos informacionais. Em seguida, podem se transformar em políticas de auxílio, que atendam às questões relacionadas ao acesso, ao uso, à compreensão e à apropriação de sentidos nos campos da ciência, da tecnologia, sociedade, saúde etc. (SILVA; SILVA; FREIRE, 2018).

No âmbito organizacional, é importante avaliar se a política informacional está ligada ao pensamento estratégico da organização, visualizando a conjuntura tendo em vista o aspecto crítico para o sucesso na tomada de decisão. É preciso perceber se existe um posicionamento coerente entre a política informacional e as demais políticas prioritárias nas organizações (de recursos humanos, financeira, investimentos etc.) e, em um contexto mais abrangente, em relação ao planejamento estratégico adotado (DUTRA; CORREA; RUAS, 2013).

Para a formulação de políticas de informação, é preciso considerar:

[...] outras perspectivas como a política, a cultural e a social, além da econômica, devam ser levadas em conta e que deva haver um equilíbrio entre a busca pelo lucro, pelo desenvolvimento inovativo, mas também a busca por valores sociais, pela importância da informação na construção social da realidade (MAGNANI; KERR PINHEIRO, 2011, p. 599).

Segundo Dutra, Correa e Ruas (2013, p. 86), "o adequado conhecimento de qual informação é estratégica para a organização pode definir a necessidade ou não de formulação/aplicação de uma política de informação”. Para que uma instituição possua uma política de informação bem estruturada e alinhada com as diretrizes estratégicas da organização, é preciso que haja o conhecimento dos vários níveis organizacionais, bem como dos ambientes que a compõem.

Isto porque as políticas de informação apresentam caminhos para uma atuação planejada de ações informacionais, sejam elas provenientes dos entes estatais, de órgãos de controle, de organizações públicas ou privadas, de comunidades científicas e civis (SILVA; SILVA; FREIRE, 2018). Segundo Silva, Silva e Freire (2018, p. 158), "[...] as políticas de informação também foram se constituindo conjunto de ações programáticas e de valores políticos e organizacionais, visando a promoção de tomadas de decisão ao acesso e uso da informação". Para esses autores, é preciso lembrar que, quanto mais estratégica e útil, mais a informação se configura nas práticas sociais, econômicas, culturais, científicas e tecnológicas.

Fundamentadas no conceito de políticas de informação formulado por Silva, Silva e Freire (2018), concebe-se o de políticas de informação ergonômicas como estratégias políticas, econômicas, sociais, culturais, legais, normativas e organizacionais que direcionam os processos de tomada de decisão, acesso e uso da informação na promoção da saúde e segurança do exercício profissional, em atendimento às características psicofisiológicas dos trabalhadores.

O estado assume papel de destaque criando, normatizando e implementando políticas de informação ergonômicas a serem adotadas nas instituições públicas e privadas como observado com a NR-17 e as demais normas regulamentadoras direcionadas à saúde e à segurança dos trabalhadores.

Para que isso ocorra, é necessário haver mudanças sociais, culturais e institucionais de valorização do ser que trabalha e que as organizações invistam em adequações estruturais, de mobiliário, de equipamentos e de condições ambientais adaptadas às condições psicofisiológicas dos profissionais. Tais investimentos trarão retornos econômicos e sociais positivos a médio e longo prazos, aumentando o índice de satisfação dos profissionais e, consequentemente, a produtividade nas instituições, além de contribuir para a diminuição do número de faltas, abstenções, licenças e afastamentos por acidentes e doenças relacionadas ao trabalho. 
Ao apropriar-se de princípios provenientes da ergonomia para criar leis, normas regulamentadoras e demais diretrizes a serem observadas por organizações públicas e privadas, o estado assume sua responsabilidade na formulação e implementação de políticas informacionais voltadas para a saúde e para a segurança ocupacional. Por serem determinações provenientes dos entes estatais - na maioria das vezes - ou das próprias instituições, as normas adquirem o caráter de políticas públicas ou institucionais, transformando as relações entre os indivíduos e seu ambiente de trabalho.

Com relação à formulação de políticas de informação ergonômicas, é preciso que a organização conheça o perfil e as demandas de seus trabalhadores, de modo que a aplicação destas políticas seja bem-sucedida e haja a efetiva adequação das condições de trabalho às suas reais necessidades, tornando possível um ambiente de trabalho confortável, saudável e seguro.

A adoção de políticas de informação ergonômicas é fundamental para promover o conforto e o bem-estar dos trabalhadores, alcançando-se, assim, a humanização das condições de trabalho. Perspectiva em que a informação estaria relacionada à ergonomia, por ser um instrumento que qualifica a consciência do indivíduo e de seu grupo social e, ao tempo em que contribui para o empoderamento dos trabalhadores, conscientizando-os da transformação de seus espaços e relações de trabalho com responsabilidade ética, social, corporal e psicológica (MORAES, 2001; FARIA; VARELA; FREIRE, 2019).

\section{2 contribuições da $\mathrm{nr}-17$ para arquivos e bibliotecas}

O Ministério do Trabalho e Emprego (MTE), foi criado em 1930, durante o governo de Getúlio Vargas e foi extinto em 2019, com suas atribuições divididas entre o Ministério da Economia, o Ministério da Cidadania e o Ministério da Justiça e Segurança Pública. A maior parte das atribuições foram concentradas na Secretaria do Trabalho, que integra o Ministério da Economia.

O MTE tinha a responsabilidade de criar políticas e diretrizes visando a geração de emprego e renda, a modernização das relações de trabalho e a fiscalização em saúde e segurança do trabalho, bem como a aplicação de penalidades cabíveis quando constatadas irregularidades ou inobservância das recomendações previstas nas legislações de Saúde e Segurança do Trabalho (SST). Cabia ainda ao MTE a responsabilidade de editar as Normas Regulamentadoras (NR) relativas à segurança e saúde do trabalho, cuja observância era obrigatória tanto para órgãos públicos quanto para empresas públicas e privadas, que possuíssem empregados regidos pela Consolidação das Leis de Trabalho (CLT).

Atualmente, existem trinta e sete NR em vigor no Brasil, entretanto, a tendência é que esse número seja reduzido para 90\%, conforme anúncio divulgado pelo atual presidente do país, Jair Messias Bolsonaro, em 13 de maio de 2019i, ao afirmar haver "custos absurdos [para as empresas] em função de uma normatização absolutamente bizantina, anacrônica e hostil”.

Em 30 de julho de 2019, o governo federal anunciou a revisão de trinta e seis das regras de proteção da saúde e da segurança de trabalhadores. Inicialmente foram anunciadas a revisão das NR-1 e NR-12, que tratam, respectivamente, das disposições gerais sobre normas de segurança no uso de máquinas e dos equipamentos do trabalho. Naquela ocasião, foi comunicada a revogação da NR-2, que recomendava aos novos estabelecimentos solicitação prévia da fiscalização trabalhista para aprovação das instalações antes do início das atividades.

As NR sobre políticas públicas foram criadas a partir de necessidades percebidas pelo estado em função de regulamentar e fornecer diretrizes necessárias à promoção da saúde e segurança do trabalho. Segundo Souza e Secchi (2015, s. p.) uma política pública é uma entidade abstrata que se materializa por instrumentos concretos, tais como programas, projetos, obras, organizações, campanhas e leis nas diversas áreas de atuação pública: saúde, educação, meio ambiente, gestão pública, infraestrutura, segurança e outras.

Para que uma política pública seja criada é necessário identificar o problema e sua necessidade; a formação de agenda de enfrentamento ao problema e de alternativas viáveis para a resolução; decisões que ajudem a implementar tais políticas; e avaliação contínua para, caso necessário, extingui-la (SECCHI, 2013). Cabe lembrar que nem sempre as etapas descritas ocorrem sequencialmente da maneira que foram criadas. As políticas públicas também podem ser extintas ou descontinuadas, mas nem sempre sua extinção objetiva o bem comum. Muitas vezes o atendimento de políticas econômicas, sociais, religiosas ou culturais, por exemplo, sobrepõem-se aos interesses do coletivo.

A revisão, possível redução, ou extinção dessas normas podem causar retrocessos e prejuízos incalculáveis em 
relação aos avanços alcançados por décadas em saúde e segurança do trabalho, afetando a vida dos trabalhadores ao aumentar os riscos de acidentes, doenças e mortes decorrentes do exercício profissional. Com relação à ergonomia, existe norma brasileira - NR-17- que trata das condições de trabalho utilizando os princípios ergonômicos como parâmetro.

Em 23 de novembro de 1990, a NR-17 foi aprovada pela Portaria 3.751 do Ministério do Trabalho e Previdência Social, conforme nomenclatura adotada a época. A norma é regulamentada por Portaria $n^{\circ} 3.214$, de 08 de junho de 1978, que aprova normas relativas à segurança e à medicina do trabalho, presentes no Capítulo V, Título II, da Consolidação das Leis do Trabalho (CLT), e estabelece parâmetros que permitem adaptar as características psicofisiológicas dos trabalhadores às condições de trabalho, proporcionando-lhes conforto, segurança e desempenho eficiente.

Quanto à adequação das condições de trabalho às características psicofisiológicas dos trabalhadores, a NR-17 atribui aos empregadores a responsabilidade de realizar a análise ergonômica do trabalho (AET), considerando, no mínimo, as condições relacionadas ao levantamento, transporte e descarga de materiais, ao mobiliário, aos equipamentos e às condições ambientais do posto de trabalho, além de sua organização.

Destaca-se também a NR-23 da Portaria 3.214 do MTE, sobre proteção a incêndio para locais de trabalho que, embora não trate especificamente de questões ergonômicas, é de extrema importância para a garantia da segurança e do bem-estar dos profissionais. Considerando a prevenção de catástrofes e acidentes relacionados a sinistros com água (inundações, infiltrações, vazamentos), recomenda-se atenção às normas NBR 5.626 e NBR 13.714, que tratam de instalações hidráulicas de combate a incêndio.

As normas referentes à prevenção de acidentes nos ambientes de trabalho têm relação direta com a ergonomia, pois auxiliam na prevenção de possíveis riscos à saúde e segurança dos trabalhadores. Riscos esses que podem ser evitados com adequações das condições de trabalho, conforme as recomendações propostas nas NBR. Ressalta-se ainda a necessidade das bibliotecas e arquivos atenderem aos requisitos previstos na NBR 9.050 sobre acessibilidade de pessoas portadoras de deficiência a edificações, espaços, mobiliários e equipamentos urbanos.

\section{Metodologia}

Esta pesquisa caracteriza um estudo entre casos de mesma natureza, com abordagem qualitativa, oferecendo liberdade em selecionar os temas e permitindo a realizar aprofundamentos sobre temática variável em linguagem simples e compreensiva (YIN, 2016).

Com relação à tipologia, enquadra-se em descritiva, relatando situações, acontecimentos, feitos e manifestações sobre o fenômeno estudado. O campo empírico é constituído por arquivos e bibliotecas das instituições públicas de ensino superior, sendo duas federais e uma estadual, situadas na cidade de João Pessoa, capital do estado da Paraíba, Brasil. Os profissionais dessas instituições que desempenham atividades em arquivos e bibliotecas, constituem os sujeitos da pesquisa, independente das funções ocupadas, quer sejam arquivistas, bibliotecários, técnicos, auxiliares ou chefes.

Para a realização das entrevistas, optou-se por um servidor que trabalhasse no arquivo e outro que atuasse na biblioteca, perfazendo o total de dois entrevistados em cada instituição, a escolha recaindo sobre aqueles que dispusessem de tempo e interesse para realização da entrevista. A observação direta dos ambientes de trabalho, a leitura do PDI e as entrevistas, tornaram possível atender ao objetivo proposto neste estudo. Na análise dos PDI, as instituições de ensino superior foram denominadas IES-A, IES-B e IES-C, objetivando preservar o sigilo de suas identidades. Na análise das entrevistas, os participantes estão denominados de E1(arq) e E1(bib) para a IES-A; E2(arq) e E2(bib) para a IES-B e E3(arq) e E3(bib) para a IES-C. Não é demais registrar que os resultados estão apresentados de forma fidedigna ao acontecido.

A categorização dos dados utiliza a perspectiva de Bardin (2009), para conduzir a interpretação dos resultados das entrevistas. As categorias estão estabelecidas com base nos elementos elencados na NR-17, que também nortearam as perguntas das entrevistas sobre levantamento, transporte e descarga individual de materiais, mobiliário e equipamentos dos postos de trabalho, condições ambientais e organização do trabalho.

\section{Resultados}

Os resultados estão expostos em duas etapas. Em primeiro lugar, aqueles obtidos por meio da leitura e análise dos Planos de Desenvolvimento Institucional (PDI) das instituições de ensino superior estudadas, para identificar metas e ações voltadas para a ergonomia. A seguir, conforme codificação e utilização de palavras-chave, são 
apresentadas as entrevistas realizadas com servidores atuantes nos arquivos e bibliotecas das instituições, a fim de conhecer as percepções acerca da atuação da instituição em relação ao (des)cumprimento das normas de ergonomia em seus ambientes e identificar as políticas de informação ergonômicas adotadas.

\subsection{Dos PDI}

O PDI é um instrumento de planejamento que orienta e auxilia as instituições quanto ao cumprimento de seus objetivos, metas, estratégias, cronograma e ações necessárias para sua concretização. Para identificar se e quais políticas de informação ergonômicas são adotadas nos arquivos e bibliotecas das instituições, realizou-se leitura dos Planos de Desenvolvimento Institucionais e entrevistas com os servidores que atuam em seus arquivos e bibliotecas.

A leitura dos três Planos permitiu identificar que inexiste menção na IES-A à palavra ergonomia, mas existem ações que, apesar de não focalizarem políticas de informação ergonômicas objetivam promover ou incentivar a saúde do trabalhador.

A IES-A exterioriza em seu PDI o objetivo de implementar sistema de gestão da segurança e da saúde ocupacional visando proteger o servidor e melhorar sua qualidade de vida. O quadro de ações e metas do setor de Gestão de Pessoas faz referência ao objetivo de promover a implementação da política em saúde do trabalhador, sem especificar que ações seriam adotadas, embora sua execução tenha sido planejada para 2015. Na análise do PDI da IES-A percebe-se ausência de discussões ou inexistência de políticas institucionais aprofundadas em busca de melhorias nos postos de trabalho, incluindo arquivos e bibliotecas e, mais especificamente, aquelas voltadas para as questões ergonômicas.

O termo ergonomia é citado no subtópico 3.3.4 da IES-B, referente à Saúde e Proteção no Trabalho dos Projetos de Extensão promovidos pela instituição. Tais projetos buscam promover saúde ocupacional por meio de programas assistenciais com a utilização de metodologias de intervenção, ergonomia, educação para a saúde, e vigilância epidemiológica e ambiental, tendo como alvo o ambiente de trabalho e como público os trabalhadores urbanos e rurais. Não cita ações visando melhorar as condições de trabalho dos servidores, ou que atentem para princípios ergonômicos relacionados à saúde e segurança do trabalho. No objetivo de adequação da infraestrutura dos campi para oferta apropriada aos cursos, uma estratégia menciona adequar as instalações físicas destes para atender as condições de acessibilidade de alunos e servidores. Essa é a referência mais aproximada relativa à ergonomia.

Da análise do PDI da IES-B, percebe-se que, apesar da referência ao termo ergonomia, sua utilização relaciona-se às atividades de extensão realizadas pela instituição. Não há menção à ergonomia que remeta à necessidade de criar ou estender - caso houvesse - políticas institucionais direcionadas à melhoria dos postos de trabalho dos servidores ou em seus arquivos e bibliotecas. Quanto a acessibilidade, no momento, está na letra do documento. Outro ponto a observar é que, embora haja na instituição academia, piscina e oferta esporádica de palestras direcionadas à saúde e segurança ocupacional, a IES-B não promove frequentemente campanhas que estimulem ou conscientizem os servidores sobre vantagens da ergonomia ou de atividades físicas para a saúde, segurança e melhoria da qualidade de vida no trabalho.

O PDI da IES-C cita o objetivo estratégicos de promover a qualidade de vida, saúde e segurança do trabalho por meio do fomento à qualidade de vida e ao bem-estar dos servidores, envolvendo fatores como saúde física e mental, clima da organização, motivação, condições salubres de trabalho, dentre outros. A ergonomia está implícita quando a qualidade de vida é citada envolvendo saúde física e mental, clima organizacional, motivação e condições salubres de trabalho. O Plano menciona metas e ações voltadas para a saúde e segurança do trabalhador. Possui seção dedicada às ações institucionais voltadas à promoção de melhoria nos postos de trabalho ou em saúde, segurança ou ergonomia no trabalho. Objetiva aumentar em 50\% o número de ações na área de saúde do servidor; ampliar em $30 \%$ o número de servidores que participam de programas de qualidade de vida e aumentar em $50 \%$ o número de ações na área de segurança no trabalho.

A leitura dos PDI permitiu constatar a escassez de políticas de informação em ergonomia nas instituições e essa situação leva a questionar se a insuficiência de políticas permanentes em ergonomia contribui para acentuar a baixa adesão dos servidores às (poucas) ações em ergonomia desenvolvidas por suas instituições.

\subsection{Das entrevistas}

Os servidores entrevistados dos arquivos das instituições analisadas tem média de idade de 37,6 anos e nas bibliotecas a média é de 49,6 anos. Quanto ao tempo de serviço nos arquivos, os entrevistados exercem suas funções nas instituições entre dois e sete anos, ou seja, todos trabalham há menos de uma década em seus respectivos cargos. Nas bibliotecas, o tempo de serviço encontra-se entre 7 e 10 anos, exceto o ocupante do cargo 
de diretor, que está na instituição desde o final da década de 1970, embora exerça tal função há 3 anos.

Recentemente, duas instituições (IES-A e IES-C) alteraram suas jornadas de trabalho, passando de seis para oito horas diárias, perfazendo a carga de quarenta horas semanais. Tal mudança foi criticada por três entrevistados, que se queixaram das dificuldades de (re)adaptação ao novo horário e do comprometimento na qualidade de vida. Apenas na IES-B, os servidores afirmaram trabalhar seis horas diárias e contínuas, embora formalmente esteja estabelecida a jornada de oito horas diárias e quarenta horas semanais de trabalho. A carga horária do entrevistado da biblioteca da IES-C possui maior variação, pois ainda que sua jornada de trabalho seja de oito horas diárias, esta pode se estender por duas horas a mais, dependendo das demandas ou necessidades. Os entrevistados da maioria das instituições afirmaram trabalhar cinco dias por semana, exceto E2(bib), que eventualmente pode trabalhar em dia de sábado, de acordo com escala previamente estabelecida.

Tendo em vista as categorias elencadas pela NR-17, sobre levantamento e transporte individual de materiais, mobiliário dos postos de trabalho, equipamentos dos postos de trabalho, condições ambientais e organização do trabalho, serão apresentados os resultados por estas categorizações, conforme anteriormente explicitadas.

\subsubsection{Levantamento e transporte individual de materiais}

Todos os profissionais de arquivos relataram levantar e transportar peso de pastas e caixas a estantes, mesas e cadeiras durante o exercício das atividades. Os servidores das bibliotecas também afirmaram que levantam e conduzem peso no decorrer de suas atividades.

Ao serem questionados sobre a instituição ter realizado treinamentos ou orientação para a execução de atividades com levantamento e condução de peso, E1(arq) e E2(arq) afirmaram não terem tido qualquer treinamento ou orientação nesse sentido. E3(arq), informou que a instituição tem um setor específico de logística, com pessoas que realizam essas tarefas. Nas bibliotecas, as respostas foram semelhantes às dos entrevistados dos arquivos, apenas E1(bib) relatou ter feito treinamento, passando por todos os setores da biblioteca central quando assumiu o cargo. Entretanto, sua resposta dá a entender que o treinamento foi dado em relação às atividades em geral e não direcionado a limite de peso transportado, ou a postura correta. E2(bib) e E3(bib) disseram não ter tido esse treinamento e/ou orientação, inclusive E3(bib) referiu que antigamente não havia preocupação das instituições com a saúde do servidor, que essa atenção é algo bem mais recente.

A posição em que a maioria dos entrevistados afirmam passar a maior parte das jornadas de trabalho é a sentada. Apenas os servidores da IES-C disseram alternar entre sentados e em pé em igual proporção de tempo. Coincidentemente, os dois servidores da IES-C ocupam cargos gerenciais e talvez, devido à natureza de seus cargos, haja a necessidade constante de resolver questões administrativas dentro de seus próprios setores e de setores externos, gerando maior variação na locomoção do que os demais servidores. Essa ideia é validada pelo pensamento de Wilhelms (2012), que sugere que a postura no trabalho deve ser determinada de acordo com a tarefa desenvolvida e/ou de acordo com o posto de trabalho. Apenas dois dos entrevistados afirmaram intercalar suas posturas ao longo da jornada de trabalho, os demais podem vir a sofrer danos futuramente por sobrecarga em seu sistema musculoesquelético.

\subsubsection{Mobiliário dos postos de trabalho}

A maioria dos servidores tanto dos arquivos quanto das bibliotecas relatou que as instituições fornecem assentos com altura ajustável. Apenas o servidor do arquivo da IES-A declarou que há só um assento com altura ajustável e que não supre as necessidades do setor que conta com dois servidores. A maior parte dos entrevistados dos arquivos e bibliotecas também reporta que a mobília não está adaptada de acordo com suas especificidades, apenas na biblioteca da IES-B, o entrevistado afirmou que o mobiliário se adequa ao seu tamanho, mas não soube informar se isto ocorre por pura coincidência.

\subsubsection{Equipamentos dos postos de trabalho}

Com relação aos equipamentos dos postos de trabalho serem adaptados às características psicofisiológicas do trabalhador e à natureza do trabalho, a IES-A não fornece equipamentos especializados nem para as funções e atividades desempenhadas em seu arquivo nem em sua biblioteca. A IES-B fornece suportes ergonômicos para os pés aos servidores do arquivo, porém não podem utilizá-los por inexistência de espaço. Para os servidores da biblioteca a IES-B fornece mousepad ergonômico, cadeiras com encosto, mas não oferece descanso para pés nem lâmpadas ou dispositivos para auxiliar a leitura ou telas que protejam a visão da radiação dos monitores dos computadores. A IES-C não possui equipamentos adaptados aos postos de trabalho, quer seja na biblioteca ou no arquivo. 
Os computadores são instrumentos imprescindíveis para atividades laborais em arquivos e bibliotecas e são usados em rotinas e atividades dos setores visitados. A observação direta e os testemunhos dos entrevistados possibilitou constatar que a adequação dos equipamentos de trabalho não constatada na maioria das instituições analisadas. Portanto, a situação encontrada nas IES não condiz com as orientações dadas por Wilhelms (2012), ao ressaltar a importância do dimensionamento da visão do monitor de vídeo, a postura do profissional, a iluminação, a temperatura e umidade e os ruídos nos postos de trabalho que utilizam computadores, possibilitando aos profissionais apresentarem dores musculares, fadiga visual, estresse etc.

\subsubsection{Condições ambientais de trabalho}

Quanto às condições ambientais, é preciso que temperatura, umidade, acústica, iluminação estejam adequadas às características psicofisiológicas dos trabalhadores e à natureza do trabalho a ser desenvolvido, para que seja possível amenizar situações que favoreçam adoecimento, tensões, desconforto e acidentes no trabalho.

Com relação à temperatura, todos os setores possuem ar-condicionado e janelas e na maioria deles, é possível alternar entre temperatura ambiente e artificial com uso do aparelho. Entretanto, E1(arq) e E2(bib) afirmaram ter problemas com a regulagem da temperatura em seus ambientes de trabalho, uma vez que esta função se encontra quebrada, o que compromete o conforto térmico nos referidos setores.

Quanto ao nível de umidade, E1(arq) afirmou que a umidade em seu setor está em níveis adequados, pois existem desumidificadores que a deixam estável entre 45 e 55\%, mas há setores onde esse controle não é feito e prolifera mofo, causando problemas de saúde em alguns servidores. E2(arq) não sabe se o nível de umidade em seu setor é adequado, pois não há equipamento para medir. E3(arq) afirmou que existem problemas com umidade no setor, pois o revestimento externo do prédio está caindo, o que causa infiltrações e aumento da umidade, contribuindo para a proliferação de fungos e mofo. E1(bib) relatou não haver controle, pois não há termo-higrômetro, desumidificador ou aquecedor, acumulando a umidade natural do ambiente com a emitida pelos aparelhos de ar-condicionado. E2(bib) e E3(bib) também consideraram que o nível de umidade não é adequado em seus setores, sem maiores especificações.

Ao serem questionados sobre o nível de ruídos em seus ambientes de trabalho, apenas E2(arq), E3(arq) e E3(bib) afirmaram considerá-los confortáveis nesse sentido. A situação não é a mesma para os demais entrevistados, E1(arq) contou que o aparelho de ar-condicionado faz um ruído que dificulta escutar outra pessoa, e que ao sair do trabalho, sente um zumbido que fica na mente após o expediente e que vem sentindo uma perda de audição, comprovada por exames de audiometria, mas não sabe se isso ocorreu por causa do trabalho, mas que é possível que ele tenha contribuido. E1(bib) disse que não há conforto quanto ao nível de ruídos, pois a biblioteca está em um ambiente improvisado, que passa constantemente por reformas e consertos que fazem barulho e afetam o bem-estar e a qualidade de vida de quem trabalha ou utiliza os serviços da biblioteca. Para a mesma pergunta, E2(bib) afirma também não haver conforto, pois as salas da biblioteca não têm acústica apropriada. Inclusive, na sala de reunião é possível escutar tudo que se discute nas reuniões e apresentações de trabalhos no ambiente vizinho, dificultando a concentração em ambas.

Apenas os servidores da IES-A afirmaram ter problemas com a iluminação em seus ambientes de trabalho.

\subsubsection{Organização do trabalho}

Quando questionados se a instituição faz cobranças quanto à produtividade, E1(arq) e E3(bib) disseram que não existem cobranças desse tipo. E2(arq) também afirmou não haver cobranças por parte da instituição, apenas sua autocobrança para realizar o trabalho o mais rápido possível e isso tem lhe causado sensação de dormência nas mãos. Segundo E3(arq) existe muita cobrança, porque o arquivo é novo e a instituição tem mais de 60 anos sem cuidados com os documentos. Tudo se encontra por fazer e há a necessidade de cuidar dos documentos digitais que estão sendo elaborados diariamente, cujo volume é assustador. E1(bib) disse que não existem cobranças diretas, apenas a responsabilidade que cada um tem de prestar bom serviço e bem atender ao usuário. E2(bib) relatou que não costuma haver cobranças relacionadas à produtividade, mas no momento existe essa cobrança, por conta de mudança de um software pago para um gratuito e um prazo determinado para realizar a migração de todo o acervo.

Ao serem questionados sobre a intensidade de seu ritmo de trabalho, E1(arq), E1(bib) e E2(bib) responderam não o considerar excessivo. Devido a cobranças autoimpostas E2(arq) afirmou que seu ritmo já foi intenso a ponto de sua mão ficar dormente. E3(arq) disse que seu ritmo de trabalho é muito intenso e E3(bib) declarou que depende do dia e de sua autodisciplina, que a faz diminuir o ritmo quando percebe acelerar demais.

Com relação ao recebimento de instruções para a realização das tarefas diárias, apenas E1(arq) e E2(arq) afirmaram não terem recebido nenhum curso ou orientação nesse sentido. Os demais entrevistados receberam 
instruções, seja por meio de capacitação e treinamento oferecidos pela instituição ou por meio de servidores que estavam no setor anteriormente e lhes repassaram as informações relevantes para as tarefas diárias.

De forma unânime, todos os entrevistados afirmaram não receber nenhum tipo de vantagem relacionada às repercussões de seu trabalho sobre sua saúde.

Quanto à realização de pausas para descanso durante sua jornada de trabalho, apenas E2(arq) e E3(arq) afirmaram não realizar tais intervalos durante suas jornadas de trabalho. E1(arq) disse que, depois de um tempo, começou a fazer mais pausas, pois percebeu que sentar em cadeiras sem ajustes e desconfortáveis estava prejudicando sua coluna e também sentiu necessidade de aliviar um pouco a mente. Assim, a cada duas horas, faz ao menos vinte minutos de intervalo. E2(bib) também falou que realiza pausas de quinze minutos durante o expediente. E1(bib) disse que seu único intervalo acontece durante o horário de almoço, igualmente como E3(bib). As pausas ou intervalos intrajornada têm como objetivo proteger a saúde física e mental do trabalhador e é um direito garantido pelo artigo 71 da CLT. Mas, no caso dos servidores públicos, não há legislação que trate dessa questão em especial. Então, convenciona-se utilizar as disposições da CLT como parâmetro. O subtópico 17.6.3 da NR-17 consta que devem ser incluídas pausas para descanso nas atividades que exijam sobrecarga muscular estática ou dinâmica do pescoço, ombros, dorso e membros superiores e inferiores.

Para qualquer trabalho contínuo cuja duração exceda 6 horas diárias, torna-se obrigatório conceder um intervalo para repouso ou alimentação, de no mínimo trinta minutos e no máximo duas 2 horas (Lei 13.467/2017). Caso a jornada de trabalho não exceda 6 horas, mas ultrapasse 4 horas, será obrigatório conceder um intervalo de 15 minutos (art. $71, \S 1^{\circ}$ da CLT). Portanto, é bem provável que os servidores entrevistados não tenham conhecimento quanto a esse direito e aqueles que disseram não realizar pausas para descanso durante suas jornadas de trabalho estejam perdendo a chance de usufruir de um direito que lhes assiste e que poderia contribuir para aliviar os níveis de estresse durante o trabalho.

Quando questionados se já houve afastamento do trabalho por período igual ou superior a 15 dias, E2(arq), E3(arq), E1(bib) e E3(bib) disseram nunca terem se afastado por esse período. E1(arq), por sua vez, afirmou ter se afastado por cerca de 21 dias, mas que não teve nenhum tipo de instrução quanto a voltar ao ritmo de trabalho gradativamente. Assim é que o ritmo de trabalho após o afastamento foi igual ao anterior. Do mesmo modo, E2(bib), que também se afastou por um período entre 15 e 20 dias, quando regressou ao trabalho, manteve o ritmo de produção do período anterior ao afastamento.

A NR-17 preconiza que, após qualquer tipo de afastamento igual ou superior a 15 (quinze) dias, deve haver retorno gradativo aos níveis de produção vigente a época anterior ao afastamento e, com base no relato dos profissionais entrevistados, não houve por parte das instituições em que trabalham o cuidado em fornecer tais instruções.

\section{Conclusões}

Os Planos de Desenvolvimento Institucional das instituições analisadas mostram que são insuficientes as políticas institucionais em ergonomia, condição confirmada pelas entrevistas com os servidores, que demonstraram desconhecimento de algumas situações e se queixaram da insuficiência de ações ou de políticas institucionais contínuas em ergonomia.

Os servidores reconhecem a importância da ergonomia para melhorar sua saúde, segurança, bem-estar e qualidade de vida no trabalho, muito embora alguns assumam não haver interesse em buscar informações ou participar de eventos, ações, cursos, palestras e treinamentos voltados para a ergonomia ou saúde e segurança no trabalho promovidos por suas instituições (ainda que tais realizações sejam escassas). A percepção da maioria dos respondentes é que suas instituições não zelam pela saúde, conforto ou bem-estar e tal entendimento contribui para desmotivação, desânimo e sensação de conformismo perante a impotência em transformar suas realidades.

Algumas ações práticas e de custo relativamente baixo podem ser realizadas em função de melhorar as condições de trabalho e amenizar a insatisfação dos servidores:

a) promover adaptações nas instalações e nos equipamentos de trabalho para atender às necessidades psicofisiológicas dos trabalhadores, atentando para as recomendações das NR referentes à saúde, à segurança e à ergonomia no ambiente de trabalho;

b) instituir no calendário institucional programas, ações e projetos permanentes em políticas de informação ergonômica, estimulando a prática de ginástica laboral, reeducação postural global (RPG), pilates, pausas para descanso, alongamentos, academia e estímulo à prática de esportes, por exemplo. Tudo visando a conscien- 
tização dos servidores acerca da importância destas ações para preservação de sua saúde e qualidade de vida e, consequentemente, contribuindo para a transformação da cultura organizacional em relação à temática;

c) estreitar a aproximação do setor de saúde do trabalhador com os servidores dos arquivos e bibliotecas, criando canais diretos de comunicação (por meio de e-mails, atendimento presencial ou via telefone, por exemplo) que estimulem sua participação nas ações em ergonomia a serem promovidas pela instituição direcionadas a seus setores;

d) permitir que as equipes atuantes nas bibliotecas e nos arquivos tenham autonomia sobre as melhores formas de realizarem suas tarefas, levando em consideração a opinião deles para o planejamento das atividades e organização do tempo de trabalho. Por outro lado, desenvolver a autoestima dos servidores, lembrando-lhes a importância de seu trabalho para a sociedade e o desenvolvimento de suas capacidades e habilidades;

e) disponibilizar atendimento psicológico para os servidores, atuando na intermediação e na resolução de possíveis conflitos, bem como estimulando o envolvimento da equipe no planejamento de mudanças, facilitando com isso sua aceitação;

f) tornar o trabalho mais flexível e menos monótono, alternando as atividades diante de telas com outras tarefas, evitando o trabalho contínuo diante delas; e, por fim,

g) estimular a prática de pausas curtas durante o trabalho, combinando-as com exercícios de alongamento e/ou relaxamento.

Mais do que responder se e como as instituições públicas de ensino superior do município de João Pessoa desenvolvem políticas de informação ergonômicas em seus arquivos e bibliotecas, essa pesquisa traz à tona a urgência em criar uma cultura organizacional voltada para a valorização da saúde dos trabalhadores. Além disso, deixa incógnitas sobre o futuro da ergonomia e da adequação dos postos de trabalho às características psicofisiológicas dos trabalhadores, que não devem se restringir apenas aos setores das instituições estudadas, mas ampliar-se de forma abrangente, considerando os desafios das constantes inovações tecnológicas e a fragilidade das relações de trabalho, que acarreta o desmonte sucessivo de direitos sociais e trabalhistas.

É preciso atentar também para as consequências que o uso cada vez mais frequente das tecnologias de comunicação (computador, smartphones e tablets) têm para a saúde dos trabalhadores de arquivos e bibliotecas. Tais instrumentos são vistos como ferramentas imprescindíveis para a execução das atividades laborais e da comunicação nos postos de trabalho. Finalmente, recomenda-se a necessidade de adequação das culturas organizacionais, de modo que estas prezem pela atenção e cuidados com a saúde e a segurança de seus trabalhadores atentando para os princípios preconizados pela ergonomia, disseminando informações que possam auxiliar na conscientização dos trabalhadores sobre a relevância desses conhecimentos para a melhoria de suas condições de trabalho e de vida.

\section{Referências}

ABRAHÃO, J.; SZNELWAR, L.; SILVINO; A.; SARMET, M.; PINHO, D. Introdução à ergonomia: da teoria à prática. 3. reimpr. São Paulo: Blucher, 2016. 240 p.

ARAÚJO, C. A. Á. Um mapa da ciência da informação: história, subáreas e paradigmas. ConCl: Conv. Ciênc. Inform., São Cristóvão/SE, v. 1, n. 1, p. 47-72, jan./abr. 2018.

BEZERRA, E. P.; SILVA, Z. C. G. da. Regime de informação: conceitos e aplicações no âmbito de laboratórios de pesquisa científica. In: ENCONTRO NACIONAL DE PESQUISA EM CIÊNCIA DA INFORMAÇÃO, 16., 2015, João Pessoa. Anais [...]. João Pessoa: ANCIB, 2015. ISSN 2177-3688.

BEZERRA, E. P.; SILVA, Z. C. G. DA; GUIMARÃES, I. J. B.; SOUZA, E. D. de. Regime de informação: abordagens conceituais e aplicações práticas. Em Questão, v. 22, p. 60-86, 2016.

BRAMAN, S. Change of State: Information, Policy and Power. Cambridge: Mit Press, 2009.

BRASIL. Constituição da República Federativa do Brasil de 1988. Brasília, DF: Presidência da República, [2016?]. Disponível em: http://www.planalto.gov.br/ccivil_03/Constituicao/ Constituiçao.htm. Acesso em: 1 jan. 2020. 
BRASIL. Ministério do Trabalho e Emprego. NR 17 - Ergonomia. Portaria MTPS n. ${ }^{\circ} 3.751$, de 23 de novembro de 1990. Disponível em: http://portal.mte.gov.br/data/files/FF8080812BE914E6012BEFBAD7064803/nr 17.pdf. Acesso em: 20 jun. 2019.

CARVALHO, R. J. M. de; SALDANHA, M. C. W.; VIDAL, M. C. R. (org.). Azimutes do trabalho: olhares da ergonomia para diversas situações. Porto Alegre: Revolução e-Book, 2017.

DUTRA, D. M. R.; CORREA, R. A.; RUAS, W. J. Política de informação nas organizações. Pós em revista, Belo Horizonte, v. 1, n. 7, p. 84-91, 2013. Disponível em: http://blog.newtonpaiva.br/pos/wp-content/uploads/2013/05/ Pos-em-Revista E7-AD13.pdf. Acesso em: 01 set. 2019.

FARIA, M. G. G.; VARELA, A. V.; FREIRE, I. M. Competência em informação para comunidades: empoderamento e protagonismo social. Perspectiva. ciênc. inf., Belo Horizonte, v. 24, n. 1, p. 4-24, mar./2019. http:/l dx.doi.org/10.1590/1981-5344/2614. Disponível em: http://www.scielo.br/scielo.php?script=sci arttext\&pi$\mathrm{d}=\mathrm{S} 1413-99362019000100004 \& \mathrm{lng}=$ en\&nrm=iso. Acesso em 20 jan. 2020.

FINAMOR, M. S.; LIMA, C. R. M. de. Bibliotecários em hospitais: práticas informacionais. P2P e inovação, [S.I.], v. 4, n. 1, p. 109-129, out. 2017. doi: https://doi.org/10.21721/p2p.2017v4n1.p109-129. Disponível em: http://revista. ibict.br/p2p/article/view/3990/3320. Acesso em: 08 ago. 2019.

FREIRE, G. H. de A. Sobre a ética da informação. In: Simpósio Brasileiro de Ética da Informação, 1., 2010, João Pessoa. Anais [...]. João Pessoa: 101 Ideia, 2010. p. 5-10. Disponível em: http://ru.ffyl.unam.mx/bitstream/handle/10391/1328/teaching\%20information\%20ethics.pdf;jsessionid=F7A87613C27FE625A4C8DFED24777350?sequence=1. Acesso em: 06 ago. 2019.

FROHMANN, B. O caráter social, material e público da informação. In: FUJITA, M. S. L.; MARTELETO, R. M.; LARA, M. L. G. de (org.). A dimensão epistemológica da Ciência da Informação e suas interfaces técnicas, políticas e institucionais nos processos de produção, acesso e disseminação da informação. São Paulo: Cultura Acadêmica; Marília: Fundepe, 2008, p.13-36.

GONZÁLEZ DE GÓMEZ, M. N. Novos cenários políticos para a informação. Ci. Inf., Brasilia, v. 31, n. 1, p. 27-40, jan./abr. 2002.

IIDA, I. Ergonomia: projeto e produção. 2. ed. São Paulo: Edgard Blücher, 2005. 614 p.

IFPB. Instituto Federal de Educação, Ciência e Tecnologia da Paraíba. Plano de Desenvolvimento Institucional - PDI 2015-2019. Artigo 16 do Decreto n 5.773 de 09 de maio de 2006. Disponível em: http://www.ifpb.edu.brl joaopessoa/institucional/planejamento-institucional/documentos-insitucionais/plano-de-desenvolvimento-institucional-2015 2019.pdf/view. Acesso em: 27 jan. 2020.

LAVILLE, A. Ergonomia. São Paulo: EPU, 1977.

MAGNANI, M. C. B.; KERR PINHEIRO, M. M. Regime e Informação: a aproximação de dois conceitos e suas aplicações na Ciência da Informação. Liinc em Revista, v.7, n. set. 2011, Rio de Janeiro, p. 593 - 610.

MORAES, A.; MONT'ALVAO; C. Ergonomia: Conceitos e Aplicações. 4. ed. Rio de Janeiro: 2AB, 2009.

MORAES; I. H. S.; GONZÁLEZ DE GÓMEZ, M. N. Informação e informática em saúde: caleidoscópio contemporâneo da saúde. Ciênc. saúde coletiva, v.12, n.3, p. 553-565, 2007. ISSN 1413-8123.

SECCHI, L. Políticas Públicas: conceitos, esquemas de análise e casos práticos. São Paulo: Cengage, 2013.

SILVA, E. M. O Pacto pela Vida no estado de Pernambuco: informação, política e poder. Orientadora: Joana Coeli Ribeiro Garcia. 2016. 230 f. Tese (doutorado). Programa de Pós-Graduação em Ciência da Informação. Universidade Federal da Paraíba, João Pessoa, 2016.

SILVA, M. B. da; SILVA, J. L. C.; FREIRE, G. H. de A. Análise sobre políticas de informação: perspectivas do regime de informação no âmbito da inclusão digital ante os livros Verde e Branco. Ci. Inf., Brasília, DF, v. 47 n. 2 , p.155-168, maio/ago. 2018. 
SOUZA, Y. H. de S.; SECCHI, L. Extinção de políticas públicas: síntese teórica sobre a fase esquecida do policy cicle. Cadernos de Gestão Pública e Cidadania. São Paulo, v. 20, n. 66, Jan/Jun, 2015.

UEPB. Plano de Desenvolvimento Institucional - PDI 2014-2022. RESOLUÇÃO/UEPB/CONSUNI/0180/2016, de 27 de setembro de 2016. Disponível em: http://proreitorias.uepb.edu.br/proplan/download/Documentos/PDIUEPB-2014-2022.pdf. Acesso em: 27 jan. 2020.

UFPB. Plano de Desenvolvimento Institucional - PDI 2019-2023. Artigo 21 do Decreto № 9.235, de 15 de dezembro de 2017. Disponível em: http://www.proplan.ufpb.br/proplan/contents/menu/ploplan/pdi. Acesso em: 27 jan. 2020.

VERDUSSEN, R. Ergonomia a racionalização humanizada do trabalho. Rio de Janeiro: Livros Técnicos e Científicos, 1978. $161 \mathrm{p}$.

WACHOWICZ, M. C. Ergonomia. Curitiba, PR: Instituto Federal do Paraná, 2013. 176 p. Disponível em: http://ead. ifap.edu.br/netsys/public/livros/LIVROS\%20SEGURAN\%C3\%87A\%20DO\%20TRABALHO/M\%C3\%B3dulo\%20 III/18\%20Ergonomia/Livro Ergonomia.pdf. Acesso em: 15 mai. 2019.

WILHELMS, T. M. S. Ergonomia em Bibliotecas. In: SANTOS, J. P. Gestão Ambiental em Bibliotecas: aspectos interdisciplinares sobre ergonomia, segurança, condicionantes ambientais e estética nos espaços de informação. Porto Alegre: Editora UFRGS, 2012, p. 37-52.

YIN, R. K. Pesquisa qualitativa do início ao fim. Tradução de Daniela Bueno. Revisão técnica de Dirceu da Silva. Porto Alegre, RS: Penso, 2016.

\section{Notas al final}

i Disponível em: https://www.valor.com.br/politica/6251967/bolsonaro-anuncia-reducao-de-90-de-normas-de-seguranca-no-trabalho. Acesso em: 20 mai. 2020. 
Políticas de informação ergonômicas voltadas ao trabalhador de arquivos e bibliotecas

\section{Dados dos autores}

Joana Coeli Ribeiro Garcia

Professora Titular do Departamento de Ciência da Informação com atuação no Programa de Pós Graduação em Ciência da Informação, da Universidade Federal da Paraíba. Doutora em Ciência da Informação pela Universidade Federal do Rio de Janeiro.

nacoeli@gmail.com

Marilia Vital Ribeiro

Mestra em Ciência da Informação pela Universidade Federal da Paraíba, Arquivista da Universidade Estadual da Paraíba.

mariliavr88@gmail.com

Received: $2020-06-15$

Accepted: 2021-07-31

\section{$(\mathrm{cc}) \mathrm{EYY}^{\mathrm{B}}$}

This work is licensed under a Creative Commons Attribution 4.0 United States License.

\section{ULIS D-Serte}

This journal is published by the University Library System of the University of Pittsburgh as part of its D-Scribe Digital Publishing Program and is cosponsored by the University of Pittsburgh Press 